\title{
UTILIZAÇÃO DO SOFTWARE DE CÓDIGO ABERTO EMSO PARA OSCILAÇÕES DE TEMPERATURA DESTINADAS A ANÁLISE DE SUA INFLUÊNCIA NA TAXA DE REAÇÃO DE POLIMERIZAÇÃO EM SUSPENSÃO DE ESTIRENO
}

\author{
R. M. LIMA ${ }^{1}$, L. F. NEIVA ${ }^{1}$ e W. M. POUBEL ${ }^{1}$ \\ ${ }^{1}$ Universidade Federal do Espírito Santo, Departamento de Engenharia Rural \\ E-mail para contato: wmpoubel@gmail.com
}

\begin{abstract}
RESUMO - Devido à importância do poliestireno (PS), em inúmeras aplicações, como por exemplo, na construção civil, em embalagens e em diversos produtos, se torna extremamente necessário o estudo de sua polimerização. Através da simulação do processo é possível descobrir melhores condições operacionais, facilitar o melhor entendimento do sistema, além de aumentar a produção. Com isso, o presente trabalho visa realizar simulações de oscilações de temperatura que serão usadas em simulações referentes à taxa de reação de polimerização em suspensão do estireno e permitir analisar a influência da variação de temperatura em um vaso de mistura através de simulação via CFD (Computational Fluid Dynamics). A simulação computacional será feita com o auxílio do software EMSO (Environment for Modeling, Simulation and Optimization), que irá modelar e simular as oscilações de temperatura, comprovando ser uma excelente ferramenta na área acadêmica.
\end{abstract}

\section{INTRODUÇÃO}

O polímero nada mais é que uma macromolécula formada a partir de inúmeras estruturas de repetição ligadas entre si, chamadas de monômeros (CALLISTER, 2008; CANEVAROLO JR, 2006). Essas unidades de repetição são denominadas grau de polimerização, à medida que este grau aumenta, as propriedades físicas dos produtos formados melhoram, o que é muito relevante, já que é de total interesse na fabricação de materiais de alta massa molecular (POUBEL, 2009). Dos polímeros, destaque-se o poliestireno (PS), constituído apenas pelo monômero de estireno e por conseguir ser facilmente moldado na presença do calor, o poliestireno é um homopolímero da classe dos termoplásticos (MARELE, 2011). Muito importante para a sociedade, o PS é um polímero muito leve de enormes aplicações, sua produção consome pouca energia e gera pequenas quantidades de resíduos sólidos e líquidos, o que explica a sua quinta posição dos termoplásticos mais consumidos do mundo, representando cerca de $7,8 \%$, atrás apenas dos 29,1\% do polietileno (PE), 20\% de polietileno tereftalato (PET), dos 18 e 15,3\% de polipropileno (PP) e cloreto de polivinila (PVC) respectivamente (JESUS, 2014; JACQUES, 2014).

Devido ao grande comércio do poliestireno e de sua enorme aplicação industrial, é de amplo interesse o estudo da polimerização do PS, pois a partir de seu conhecimento é possível à busca de melhores condições de operação, na segurança do processo, no aumento da 
qualidade e na produção do produto além da otimização do processo (PEREIRA, 2012; ALMEIDA, 2004).

Para a simulação da polimerização do estireno será utilizado o software EMSO (Environment for Modeling, Simulation and Optimization). Programa brasileiro desenvolvido com o intuito de oferecer ferramentas para a resolução de problemas de equações algébricodiferenciais de dimensões elevada, sendo assim aplicado em diferentes áreas da engenharia (SARTOR, 2009). O programa faz uso de conceitos da programação orientada a objetos, como composição e herança. Através da herança é possível desenvolver modelos mais complexos por meio de outros pré-existentes, adicionando derivações entre eles; já a composição permite ao usuário criar um modelo a partir de vários outros modelos independentes (FRANCISQUETTI, 2014, RODRIGUES et al, 2006).

A linguagem de modelagem do EMSO é estruturada em três entidades essenciais: Model, Device e FlowSheet. A entidade Model faz uso das seções PARAMETERS, VARIABLES e EQUATIONS, onde serão declaradas as constantes e variáveis do processo para posterior aplicação das equações do modelo. O Device é a reprodução dos equipamentos do processo, onde sua descrição matemática é descrita pelo Model. Já o FlowSheet representa o fluxograma do processo, utilizando um conjunto de modelos determinados na seção Devices (RODRIGUES et al, 2006).

O software é um projeto realizado pelo Ambiente Livre para Simulação, Otimização e Controle de Processos (ALSOC) da Universidade Federal do Rio Grande do Sul e apresenta um ambiente gráfico completo, onde permite ao usuário modelar processos tanto em estado estacionário quanto estado dinâmico. O EMSO permite também ao programador desenvolver os seus próprios modelos utilizando a linguagem do software ou utilizar as já desenvolvidas na biblioteca (EML - EMSO Model Library) (Project ALSOC, 2014; SOARES, 2007).

O objetivo desse trabalho foi analisar a influência das oscilações de temperatura na taxa de reação de polimerização do poliestireno, utilizando o software EMSO, consolidando-o como uma ferramenta acadêmica poderosa. Procura-se compreender de que forma essas oscilações podem alterar as características cinéticas. Para atingir esse objetivo, diferentes casos característicos foram analisados, considerando que as partículas experimentam campos oscilatórios de temperatura ao longo do tempo.

\section{METODOLOGIA}

No processo de polimerização, para simular e analisar a influência da temperatura ao longo da trajetória das partículas no interior do reator foi utilizado uma função oscilatória, na forma senoidal, na temperatura sobre o comportamento do sistema de polimerização. Em um reator, próximo de suas paredes, devido à camisa de resfriamento, as temperaturas são menores, e consequentemente, quanto mais distante, maiores são as temperaturas.

Uma partícula suspensa no interior de um reator de polimerização heterogênea percorre uma trajetória na qual pode ser exposta a variações de temperatura consideráveis. É relevante a consideração da realidade de que nas proximidades da parede dos reatores as temperaturas são mais baixas, enquanto as temperaturas são mais elevadas no interior do mesmo reator 
analisado. Compreender como essa partícula responde a tais variações pode revelar se a hipótese de uniformidade dos campos de temperatura é mesmo razoável.

Assim, admite-se então que a temperatura de reação varia em torno de uma temperatura média. A equação que foi implementada no software EMSO para representar a variação da temperatura é dada pela Equação 1:

$$
\mathrm{T}(\mathrm{t})=\mathrm{A} \cdot \operatorname{sen}(2 \cdot \pi \cdot \omega \cdot \mathrm{t})+\mathrm{T}_{0}
$$

Onde A é a amplitude, $\omega$ a frequência da oscilação, t é o tempo em segundos e $\mathrm{T}_{0}$ é a temperatura inicial.

\section{RESULTADOS}

A Figura 1 abaixo mostra o comportamento das oscilações da temperatura em torno de uma média.

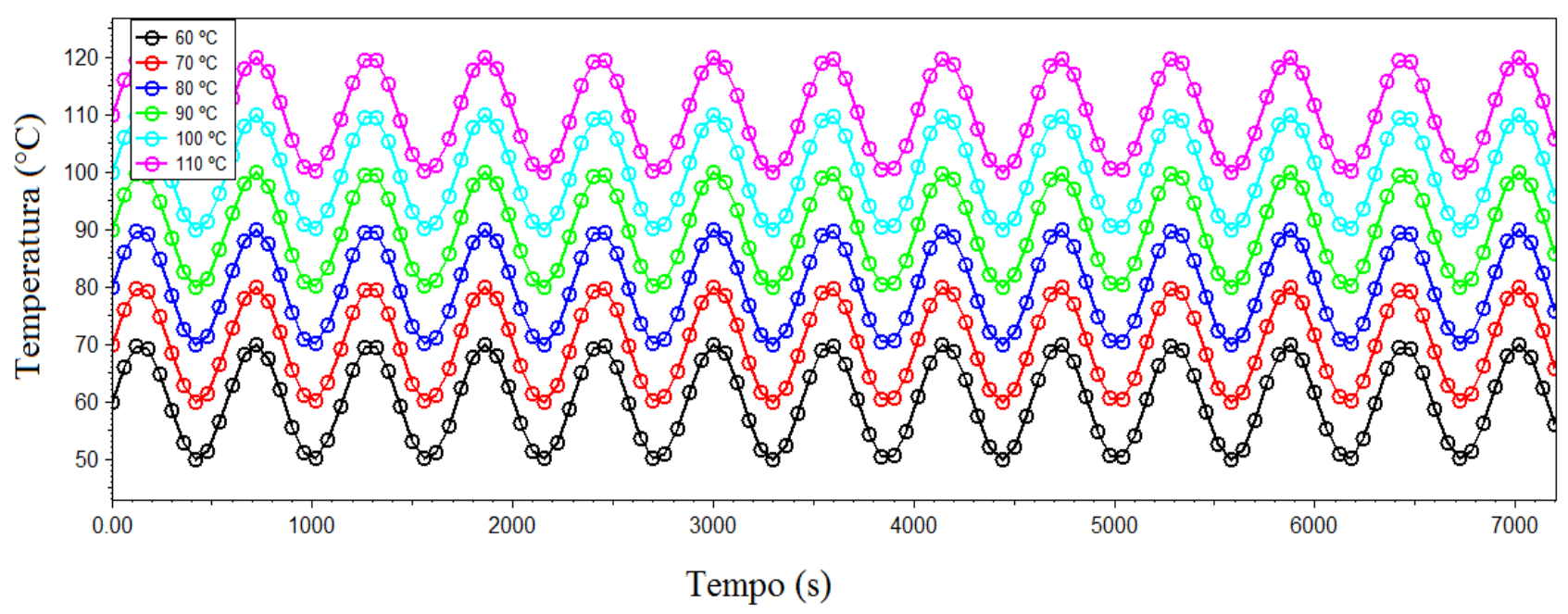

Figura 1 - Perfil de comportamento das oscilações de temperatura.

As simulações foram realizadas com frequências de $0,1 \mathrm{~s}^{-1}$, com temperaturas médias de 60 a $110^{\circ} \mathrm{C}$ e com amplitude de $10^{\circ} \mathrm{C}$ sendo que em sistemas reais a variação de temperatura não alcançam diferenças de $20^{\circ} \mathrm{C}$.

Analisando a Figura 1 pode-se perceber que a simulação do comportamento das oscilações de temperatura das partículas sólidas em um reator condiz com as variações observadas em sistemas reais de polimerização, demonstrando um desempenho satisfatório do modelo implementado. É possível destacar também a facilidade da utilização do software EMSO, com uma interface agradável e dinâmica, o programa confirma ser uma ferramenta de modelagem poderosa e justificando ser uma excelente ferramenta acadêmica.

A partir desse estudo, essas oscilações de temperatura serão implementadas em reações de polimerização em suspensão de estireno na presença de peróxido de benzoíla (Lenzi et al., 2004). E servirão de base para a aplicação de ferramentas de CFD que serão usadas para 
caracterizar o desenvolvimento de campos de temperatura e concentração em vasos de mistura e os efeitos causados sobre a operação.

\section{CONCLUSÃO}

O software de código aberto EMSO quando aplicado em um processo de variação de temperatura se demonstrou ser uma ferramenta extremamente prática e satisfatória para a resolução de problemas de modelagem, já que resolveu sem nenhuma dificuldade o sistema proposto, comprovando assim ser extremamente viável a sua aplicação tanto para aprendizagem em salas de aula, quanto para sua utilização em linhas de pesquisa e indústrias.

As análises de aplicação do EMSO se apresentaram bastante satisfatórias. Tais análises geraram resultados que serão fundamentais na simulação de reações de polimerizações em suspensão do estireno, que serão conduzidas também através do software EMSO. Esse estudo se apresenta bastante pertinente para o início de novos trabalhos em simulações que serão conduzidas via CFD para análise da variação de campos de temperatura e concentração em tanques agitados.

\section{REFERÊNCIAS}

ALMEIDA, A. S. P. N. Simulação de reatores de polimerização de estireno: Modelagem cinética e termodinâmica. Dissertação de Mestrado - Programa de Pós-Graduação em Engenharia Química, Escola de Engenharia, Universidade Federal do Rio Grande do Sul, Porto Alegre, 2004.

CALlisteR, W. D. Ciência e engenharia de materiais uma introdução. $7^{\mathrm{a}}$ Ed. Rio de Janeiro: LTC, 2008.

CANEVAROLO JR, S. V. Ciência dos polímeros: um texto básico para tecnólogos e engenheiros. 2a Ed. São Paulo: Artliber, 2006.

FRANCISQUETTI, M. C. C. Modelagem, simulação e otimização de processos usando o software EMSO (Environment for Modeling, Simulation and Optimization). Monografia - Engenharia Química, Universidade Federal de Uberlândia, Uberlândia, 2014.

JACQUES, F. B. Mercado brasileiro de poliestireno com ênfase no setor de eletrodomésticos. Monografia - Escola de Engenharia, Universidade Federal do Rio Grande do Sul, 2014.

JESUS, L. C. C. Obtenção e caracterização de compósitos de poliestireno expandido pósconsumo reforçado com celulose de bagaço de cana-de-açúcar. Dissertação de Mestrado - Programa de Pós-Graduação em Integridade de Materiais da Engenharia, Faculdade UnB GAMA e Faculdade de Tecnologia, Universidade de Brasília, Brasília, 2014.

LENZI, M. K., LIMA E. L., PINTO J. C., Modelagem da Polimerização Simultânea de Estireno em Suspensão e Emulsão, Polímeros: Ciência e Tecnologia, v. 14, no. 2, p. 112-121, 2004.

MARELE, C. P. R. Síntese e caracterização de padrão de poliestireno para cromatografia de permeação em gel através da polimerização via radical livre controlada mediada por 
radicais nitróxidos. Dissertação de Mestrado - Faculdade de Engenharia Química, Universidade Estadual de Campinas, Campinas, 2011.

PEREIRA, J. O. Modelagem e simulação de reatores de polimerização em massa de estireno com iniciadores multifuncionais. 2012. Dissertação de Mestrado - Programa de PósGraduação e Pesquisa em Engenharia, COPPE, Universidade Federal do Rio de Janeiro, Rio de Janeiro, 2012.

POUBEL, W. M. Análise de efeitos de mistura em reatores de polimerização do tipo tanque usando ferramentas de CFD. 2009. Dissertação de Mestrado - Programa de PósGraduação em Engenharia Química, COPPE, Universidade Federal do Rio de Janeiro, Rio de Janeiro, 2009.

Project ALSOC. Disponível em: <http://www.enq.ufrgs.br/trac/alsoc>. Acesso em: 17 nov. 2014.

RODRIGUES, R.; GUERRA, C. D. W.; SECCHI, A. R.; LANSARIN, M. A. Ensino de cinética e cálculo de reatores químicos utilizando o simulador EMSO. XVI Congresso Brasileiro De Engenharia Química, realizado em Lorena, em setembro de 2006.

SOARES, R. P. EMSO Manual. 2007. 